\title{
Shift of symbiont communities in Acropora tenuis juveniles under heat stress
}

\author{
Makiko Yorifuji ${ }^{\text {Corresp., }}{ }^{1}$, Saki Harii ${ }^{\text {Corresp., }}{ }^{1}$, Ryota Nakamura ${ }^{2}$, Masayuki Fudo ${ }^{3}$ \\ ${ }^{1}$ Sesoko Station, Tropical Biosphere Research Center, University of the Ryukyus, Mobotu, Okinawa, Japan \\ 2 Fisheries Infrastructure Development Center, Chuo, Tokyo, Japan \\ 3 Fisheries Agency, Ministry of Agriculture, Forestry and fisheries, Chiyoda, Tokyo, Japan \\ Corresponding Authors: Makiko Yorifuji, Saki Harii \\ Email address: makikoyorifuji@gmail.com, sharii@lab.u-ryukyu.ac.jp
}

Ocean warming is a major threat to coral reefs, leading to an increasing frequency and amplitude of coral bleaching events, where the coral and its algal symbiont associations breakdown. Long-term change and resilience of a symbiont community in coral juveniles is thought to be one of the most important aspects for determining thermal tolerance of the coral holobionts; however, despite its importance, they are not well documented in both under elevated temperature and even under natural condition. Here we investigated changes in symbiont communities in juveniles of the coral Acropora tenuis under controlled heat stress conditions $\left(30^{\circ} \mathrm{C}, 31 / 32{ }^{\circ} \mathrm{C}\right.$ ) and natural variations in seawater temperatures $\left(19-30{ }^{\circ} \mathrm{C}\right.$ ) for up to four months. Compared with the ambient temperature conditions, coral survival rates were higher when exposed to $30^{\circ} \mathrm{C}$, but survival rates decreased when exposed to $31 / 32{ }^{\circ} \mathrm{C}$. Symbiodinium types $\mathrm{A} 3, \mathrm{C} 1$, and D1-4 were detected in the juveniles under all thermal conditions; however, in higher water temperatures $\left(31 / 32{ }^{\circ} \mathrm{C}\right)$, both the prevalence of D1-4 Symbiodinium and the number of juveniles harboring only this type of symbiont increased after two to four months later. In contrast, colonies at lower temperatures $\left(30^{\circ} \mathrm{C}\right.$ and ambient) harbored multiple clades of symbionts over the same experimental period. These results highlight the flexibility of the coral- Symbiodinium symbiosis for juvenile $A$. tenuis under variable thermal conditions. In particular, the benefit of the preferential association with type D1-4 can be considered as a response when under heat-stress conditions, and that could help corals to cope with ocean warming. 
1 Shift of symbiont communities in Acropora tenuis juveniles under heat stress

2

3

4 Makiko Yorifuji $^{*}$, Saki Harii ${ }^{*}$, Ryota Nakamura ${ }^{2}$, Masayuki Fudo ${ }^{3}$

5

6

$7{ }^{1}$ Sesoko Station, Tropical Biosphere Research Center, University of the Ryukyus, 3422 Sesoko,

8 Motobu, Okinawa 905-0227, Japan

9 2Fisheries Infrastructure Development Center, 2-14-5 Tsukiji, Chuo, Tokyo 104-0045, Japan

$10{ }^{3}$ Fisheries Agency, Ministry of Agriculture, Forestry and fisheries, 1-2-1 Kasumigaseki,

11 Chiyoda-ku, Tokyo 100-8907, Japan

12 *E:mail: makikoyorifuji@gmail.com (MY), sharii@lab.u-ryukyu.ac.jp (SH) 


\section{ABSTRACT}

Ocean warming is a major threat to coral reefs, leading to an increasing frequency and amplitude of coral bleaching events, where the coral and its algal symbiont associations breakdown. Longterm change and resilience of a symbiont community in coral juveniles is thought to be one of the most important aspects for determining thermal tolerance of the coral holobionts; however, despite its importance, they are not well documented in both under elevated temperature and even under natural condition. Here we investigated changes in symbiont communities in juveniles of the coral Acropora tenuis under controlled heat stress conditions $\left(30{ }^{\circ} \mathrm{C}, 31 / 32{ }^{\circ} \mathrm{C}\right)$ and natural variations in seawater temperatures $\left(19-30{ }^{\circ} \mathrm{C}\right)$ for up to four months. Compared with the ambient temperature conditions, coral survival rates were higher when exposed to 30 ${ }^{\circ} \mathrm{C}$, but survival rates decreased when exposed to $31 / 32{ }^{\circ} \mathrm{C}$. Symbiodinium types A3, C1, and D14 were detected in the juveniles under all thermal conditions; however, in higher water temperatures $\left(31 / 32^{\circ} \mathrm{C}\right)$, both the prevalence of D1-4 Symbiodinium and the number of juveniles harboring only this type of symbiont increased after two to four months later. In contrast, colonies at lower temperatures $\left(30^{\circ} \mathrm{C}\right.$ and ambient) harbored multiple clades of symbionts over the same experimental period. These results highlight the flexibility of the coral-Symbiodinium symbiosis for juvenile $A$. tenuis under variable thermal conditions. In particular, the benefit of the preferential association with type D1-4 can be considered as a response when under heatstress conditions, and that could help corals to cope with ocean warming. 


\section{INTRODUCTION}

Coral reefs are currently being threatened by global warming and local stressors such as ocean warming (Hoegh-Guldberg 1999; Hoegh-Guldberg et al. 2007). Increasing seawater temperatures cause coral bleaching (breakdown of the coral and its algal symbiont association), and sometimes mortality (Hoegh-Guldberg 1989; Weis et al. 2008). Massive bleaching events over recent decades have caused damage to many coral reefs (Hoegh-Guldberg 1999; Hughes et al. 2017; Kayanne et al. 2002; Loya et al. 2001) and shifts in the dominant coral taxa have occurred on many coral reefs (Harii et al. 2014; van Woesik et al. 2011). Coral endosymbionts are dinoflagellates of the genus Symbiodinium, commonly known as zooxanthellae (Muscatine \& Porter 1977). Recent molecular phylogenetic analyses have revealed that the genus Symbiodinium contains nine highly divergent genetic lineages, clades A-I (Pochon \& Gates 2010). Subsequently, these groups have been further subdivided into numerous subclades or types (Coffroth \& Santos 2005).

Facing environmental stressors (e.g. heat, solar irradiance), some of the clades and/or types of Symbiodinium exhibit different physiological responses, which contribute to the degree of stress tolerance and/or resilience of the coral holobiont (i.e. coral host + Symbiodinium) (DeSalvo et al. 2010; Kinzie III et al. 2001; Rowan 2004; Sampayo et al. 2008; Suggett et al. 2008; Tchernov et al. 2004). In some scleractinian corals, the relative abundances of certain symbiont genotypeshave shifted after bleaching events or high thermal conditions (Baker et al. 2004; Glynn et al. 2001; Jones et al. 2008; Rowan 2004; Toller et al. 2001), although this is not always the case (Stat et al. 2009). For example, in 1997 in Panama, corals in the genus Pocillopora, harboring clade C Symbiodinium, were bleached; subsequently, the percentage of corals that harbored clade D increased from 43\% to 63\% (Baker et al. 2004). In 2006 on Keppel Island, part of the Great Barrier Reef, Acropora millepora corals, which initially harbored type 
62 C2 Symbiodinium, changed their symbionts to either type D or C1 after a bleaching event (Jones

63 et al. 2008). Another report indicates that $A$. millepora corals changed their symbionts from type

64 C2 to type D after transplantation to a location with higher seawater temperatures (Berkelmans \&

65 van Oppen 2006). In Florida, Montastraea cavernosa corals, which normally host type C3

66 Symbiodinium, developed a new association with type D1a Symbiodinium after a 10-day

treatment at $32{ }^{\circ} \mathrm{C}$ (Silverstein et al. 2015). Overall, many corals harboring clade D

Symbiodinium showed higher thermal tolerance and resistance to bleaching events than those

harboring clade C. Although, one report states that Acropora tenuis juveniles, artificially infected

with type C1 Symbiodinium, showed a higher heat tolerance than those infected with type D symbionts (Abrego et al. 2008).

Many of the broadcast-spawning corals (about 80\%) acquire their symbionts from the surrounding environment (horizontal transmission) during the early stages of their life history, while the other corals acquire symbiotic algae from their parents (vertical transmission) (Baird et al. 2009). In the case of horizontal transmitters, juvenile corals can acquire various types of Symbiodinium; in contrast, adult colonies are restricted to more specific types of symbionts (Little et al. 2004; Rodriguez-Lanetty 2004; Rodriguez-Lanetty et al. 2006). For example, in the Great Barrier Reef, Acropora longicyathus juveniles harbor clades A, C, or D Symbiodinium or a combination thereof, whereas the adults harbor clade A and/or C (Gómez-Cabrera et al. 2007). In addition, juveniles of $A$. tenuis and A. millepora from the Great Barrier Reef harbor type $\mathrm{C} 1$ and/or type D Symbiodinium, while the adults typically harbor only one of these types, but not both, as was shown using the nuclear ribosomal DNA internal transcribed spacer 1 (nrITS1) types (Abrego et al. 2009; Little et al. 2004), although a more recent study has shown that $A$. millepora corals in the Great Barrier Reef harbor both C1 and D types (Bay et al. 2016). On Ishigaki Island, Okinawa, types A1, A3, D1, D4, and several types of clade C were detected in 
86

87

88

89

90

91

92

several acroporid juveniles, while the adults, which mainly harbored type C2 (both nrITS1 and ITS2 types) (Yamashita et al. 2013; Yamashita et al. 2014). Although changes in symbiont type have been well documented for adult corals exposed to high seawater temperature, there is still a gap in our understanding of the responses of coral-Symbiodinium associations at the juvenile stage under such stressful conditions. The types of Symbiodinium acquired by juvenile corals may change when the corals experience abnormally high seawater temperatures, especially during the summer. Related to this point, Abrego et al. (2012) examined symbiont types in $A$. tenuis and A. millepora juveniles during the onset of symbiosis under high temperature conditions. They found that the juveniles mainly acquired type D Symbiodinium at $30^{\circ} \mathrm{C}$ and/or $31{ }^{\circ} \mathrm{C}$, whereas only type $\mathrm{C} 1$, or an equal number of types $\mathrm{C} 1$ and $\mathrm{D}$, were found at $28^{\circ} \mathrm{C}$. Their study showed potential symbiont selection by coral juveniles under different temperature conditions; however, since this experiment was performed over a short period (one month), it is unclear whether the symbiont types acquired by coral juveniles will be maintained in later life stages.

In this study, we investigated changes in the associated Symbiodinium communities of coral juveniles under high seawater temperatures for a long-term period of two or four months. In addition, Symbiodinium communities in surviving individuals were monitored for up to 1.5 years. We examined A. tenuis, which is commonly distributed in the Pacific region (Veron 2000), and is a heat-stress-sensitive species compared with other coral species (Carpenter et al. 2008). A. tenuis acquires its symbionts through horizontal transmission, and juveniles of the species can obtain multiple types of Symbiodinium (Abrego et al. 2009; Little et al. 2004; Yamashita et al. 2014; Yuyama et al. 2012; Yuyama et al. 2005). 
110

111

112

113

114

115

116

117

118

119

120

121

122

123

124

125

126

127

128

129

130

131

132

133

\section{MATERIALS AND METHODS}

Preparation of coral juveniles

Parental A. tenuis colonies were collected in 2010 from Aka Island, Okinawa, Japan (26.19

${ }^{\circ} \mathrm{N}, 127.29^{\circ} \mathrm{E}$ ), and were maintained in an outdoor tank with unfiltered running seawater on the island. The same set of four parental coral colonies spawned on June 10, 2012 and June 1, 2013; their gametes were mixed to allow fertilization to occur and resulting embryos were cultured until they developed into planula larvae. Planulae were subsequently transferred to new tanks with preconditioned terracotta tiles for settlement. Tiles were $10 \mathrm{~cm}^{2}$ in size, and were soaked in the sea off the island for two months prior to coral spawning, allowing for the development of natural biofilm layers. After larval settlement, the tiles were kept in an outdoor tank with unfiltered running seawater to promote Symbiodinium acquisition from natural seawater until the experiment commenced.

\section{Temperature treatments and collection of coral juveniles}

The coral juveniles were transferred to a set of experimental tanks on Aka Island one month after settlement in 2012 and two months after settlement in 2013. Three seawater temperature conditions were used: i) ambient seawater ranged $22.66-30.82{ }^{\circ} \mathrm{C}$ in 2012 and $27.01-30.93{ }^{\circ} \mathrm{C}$ in 2013 (Fig. S1); ii) moderate heat-stress temperatures of $30^{\circ} \mathrm{C}$; and iii) high heat-stress temperatures of $31{ }^{\circ} \mathrm{C}$ in 2012 or $32{ }^{\circ} \mathrm{C}$ in 2013 . Two and three independent tanks for each temperature condition were prepared in 2012 and 2013, respectively (Fig. S2). The heat temperature conditions in the experimental tanks were regulated and controlled by heaters (TH21; Nittokizai Co. Ltd., Japan) and thermostats (RL-200N; Marugo, Japan). The water temperatures were recorded hourly by thermo loggers during experimental periods (HOBO Water Temp Pro v2 U22-001; Onset Computer Corporation, USA); one logger was set in one of 
each temperature treatment tanks. The average \pm SD of recorded temperatures in the heated experimental tanks were $29.78 \pm 0.42{ }^{\circ} \mathrm{C}$ (for $30{ }^{\circ} \mathrm{C}$ ) and $30.83 \pm 0.89{ }^{\circ} \mathrm{C}$ (for $31 / 32{ }^{\circ} \mathrm{C}$ ) in 2012 , and between $30.06 \pm 0.17{ }^{\circ} \mathrm{C}$ (for $30{ }^{\circ} \mathrm{C}$ ) and $32.06 \pm 0.34{ }^{\circ} \mathrm{C}$ (for $31 / 32{ }^{\circ} \mathrm{C}$ ) in 2013 . The tanks were placed under natural sunlight, which was reduced with a transparent plastic roof and a black mesh. The daily maximum light intensity (measured as photosynthetic active radiation, PAR) in the tanks was measured by a light intensity logger (ALW-CMP, JFE Advantech, Japan) for approximately one week each month during the experiment. The average daily maximum light intensity during the experiments was $196.8 \mu \mathrm{mol}$ photon $/ \mathrm{m}^{2} / \mathrm{s}$ (range $41.1-436.3 \mu \mathrm{mol}$ photon $/ \mathrm{m}^{2} / \mathrm{s}$ ). In each tank, 250-400 colonies of coral juveniles were reared on six to ten tiles. All experimental tanks were $100 \mathrm{~L}$ in volume and were supplied with $10 \mathrm{~L}$ unfiltered running seawater every hour. Because coral juveniles in 2012 survived exceedingly well for up to four months, even at $31{ }^{\circ} \mathrm{C}$ with two replicate tanks for each condition, experimental conditions were changed slightly between the two years. In $2013,32^{\circ} \mathrm{C}$ of high heat stress and three replicate tanks were set in order to provide clearer results.

Coral juveniles were observed and collected after two weeks, and then monthly for four months after the heat experiment began in 2012. In 2013, coral juveniles were collected and observed after one, two, three, and five months. In 2012, juveniles that survived more than four months were continuously reared in the temperature-maintained tanks and collected 1.5 years later. On each observation date, the numbers of live individuals (colonies) were visually counted for survivorship, and then 10-30 total individuals including several backup specimens were collected from each tank (randomly from several tiles) to measure growth and to identify the associated symbiont communities. Growth of the juveniles was measured by the size of their skeletons. The major and minor axes of their undersides were measured and the general mean diameter (GMD: square root of the product of the two numbers) was calculated. Juveniles were 
158 then fixed in $99.5 \%$ ethanol for genetic analyses. The tips of the branches (approximately 1-2

$159 \mathrm{~cm}$ ) of the four adult parent corals that were used to obtain gametes were also collected and fixed

160 for genetic analyses in November 2012.

161

162

163

164

165

166

167

168

169

170

171

172

173

174

175

176

177

178

179

180

181

\section{Genetic analyses of Symbiodinium communities}

Total DNA from both juvenile and adult coral samples was extracted with guanidine solution using the method described by Sinniger et al. (2009). The clades/types of Symbiodinium spp. were identified by comparing differences in their nrITS2 sequences. Denaturing gradient gel electrophoresis (DGGE) was used to separate the PCR products. Since coral juveniles are small and the density of symbionts in some colonies was expected to be low, nested PCR was conducted to obtain target DNA fragments as follows: the nrITS region was amplified in the first reaction using the primer pair ZITSUPM13/ZITSDNM13 (Santos et al. 2001) and the amplification conditions described by the designers. In the second reaction, the nrITS 2 region was amplified using the first PCR product with primer pair ITSint-for2/ITS2CLAMP (LaJeunesse \& Trench 2000). The amplification conditions were described by LaJeunesse et al. (2003). The amplified nrITS2 PCR products were separated by DGGE as described by LaJeunesse and Trench (2000) with modifications following Yorifuji et al. (2015), using the BioRad DCode System (Bio-Rad Laboratories, Inc., USA).

To identify the clades and types of associated Symbiodinium spp., unique DGGE bands were selected from their profiles (derived from 29 colonies in 2012 and 44 colonies in 2013) and sequenced. DNA fragments in the target DGGE bands were amplified using the primers ITSintfor 2 and ITS2 rev (reverse primer without the GC-rich clamp) with the following thermal cycling profile: initial denaturation at $94{ }^{\circ} \mathrm{C}$ for $5 \mathrm{~min} ; 35$ cycles of denaturation at $94{ }^{\circ} \mathrm{C}$ for $45 \mathrm{~s}$, annealing at $52{ }^{\circ} \mathrm{C}$ for $45 \mathrm{~s}$, and extension at $72{ }^{\circ} \mathrm{C}$ for $60 \mathrm{~s}$; and a final extension at $72{ }^{\circ} \mathrm{C}$ for 10 
182 min. These PCR products were purified and sequenced by the Sanger (dye-terminator) method performed by Macrogen Japan (http://www.macrogen-japan.co.jp/), using the primer pair ITSintfor2/ITS2 rev. The obtained sequence data were edited and assembled using ATSQ, version 6.0.1 (Genetyx Co., Japan), and identified through BLAST searches of the International Nucleotide Sequence Database (INSD) and the GeoSymbio database (Franklin et al. 2012), which provides alignments of Symbiodinium nrITS2 sequences that were published between 1982 and 2012.

\section{Statistical analyses}

Growth of the corals was estimated from the mean values of their skeleton sizes in each experimental tank and then compared across temperature conditions using the Wald test under a generalized linear model (GLM). Survival curves of the coral juveniles were estimated using survival curve models with the Kaplan-Meier method and compared across temperature conditions using the two-sided log-rank test.

The coral-Symbiodinium partnership patterns, as a function of different temperature treatments, were evaluated through the DGGE profiles obtained. The prevalence of the Symbiodinium types and the composition of the symbionts were used as indicators of the symbiont communities, since some corals harbored a single type of Symbiodinium, while others harbored multiple types. The percentage of coral juveniles harbored each Symbiodinium type was calculated based on the number of host colonies analyzed under each temperature condition (referred to as "prevalence" of symbiont type). The symbiont composition for each host colony was represented by the DGGE profile (band pattern) obtained. The number of individual hosts at each temperature that harboring the same symbionts was counted based on the DGGE profiles, and the proportions of juveniles with similar symbiont compositions at each temperature were 
206

207

208

209

210

211

212

213

214

215

216

217

218

219

220

221

222

223

224

225

226

227

228

229

calculated. Comparisons of symbiont prevalence and symbiont composition at the various temperatures were made separately for the colonies collected at the beginning and end of the experiment for each year, using the Fisher's exact test. Subsequently, a cluster analysis was performed to evaluate the similarities of symbiont compositions under the three temperature treatments over the experimental time course. Sets of Euclidian distances between treatments and sampling times were calculated from the juvenile proportions of the symbiont composition data. A hierarchical cluster analysis was conducted using the unweighted pair-group method and the arithmetic mean based on Euclidian distances. All statistical analyses above were performed using the statistical package R, version 3.0.2 (R Core Team 2013).

\section{RESULTS}

\section{Survivorship and growth of coral juveniles}

The $A$. tenuis juveniles in all the treatments survived for up to four months after the experiment began in 2012 (Fig. 1A). Survival rates were $24.4 \%$ (ambient) and $14.0 \%\left(31^{\circ} \mathrm{C}\right)$ at four months. Corals in the $30{ }^{\circ} \mathrm{C}$ tanks survived up to 1.5 years, with a $37.0 \%$ survivorship at four months. In 2013 , coral juveniles in the $32{ }^{\circ} \mathrm{C}$ and ambient tanks survived only two months (Fig. 1B). Survival rates were $15.2 \%$ (ambient), $51.3 \%\left(30{ }^{\circ} \mathrm{C}\right)$, and $3.4 \%\left(32{ }^{\circ} \mathrm{C}\right)$ at two months. Survivorship in both heated treatments was significantly different from ambient survivorship for both years $(P<0.001$ by the two-sided log-rank test $)$.

The GMDs of the coral juveniles in 2012 ranged from $1.3 \pm 0.28 \mathrm{~mm}$ (ambient) to $1.5 \pm 0.35$ $\mathrm{mm}\left(31^{\circ} \mathrm{C}\right)$ on the first day of temperature treatments; four months later, the GMDs ranged from $3.4 \pm 1.06 \mathrm{~mm}\left(31^{\circ} \mathrm{C}\right)$ to $3.9 \pm 0.87 \mathrm{~mm}$ (ambient) (Fig. 2A). The growth of the corals under heated conditions was not significantly different from that of the ambient treatment group $(P=$ 
2300.09 at $30{ }^{\circ} \mathrm{C}, P=0.25$ at $31{ }^{\circ} \mathrm{C}$, Wald test under GLM). Sizes in 2013 ranged from $1.5 \pm 0.40$

$231 \mathrm{~mm}\left(32{ }^{\circ} \mathrm{C}\right)$ to $1.8 \pm 0.39 \mathrm{~mm}$ (ambient) on the first day of the experiment; two months later,

232 sizes ranged from $1.8 \pm 0.50 \mathrm{~mm}\left(32^{\circ} \mathrm{C}\right)$ to $2.2 \pm 0.43 \mathrm{~mm}$ (ambient) (Fig. 2B). The growth rates

233 of the corals under the heated conditions were not significantly different from those of the

234 ambient group $\left(P=0.32\right.$ at $30^{\circ} \mathrm{C}, P=0.86$ at $32{ }^{\circ} \mathrm{C}$, Wald test under GLM $)$.

235

236

237

\section{Symbiont types in coral juveniles and adults}

238

239

240

241

242

243

244

245

246

247

248

249

250

251

252

253

In coral juveniles at all temperatures, four major bands were detected in the DGGE gels (Fig. $\mathrm{S} 3$ ), and these four bands corresponded to four specific sequences of Symbiodinium-A3, C1, D1, and D1a - according to the nrITS2 sequences (identical to INSD sequences AF333507, AF333515, AF334660 (LaJeunesse 2001), and AF499802 (LaJeunesse 2002), respectively). In addition, a novel type of clade F Symbiodinium was detected from one colony that was reared in an ambient tank one month after the experiment began in 2012. This sequence was deposited in the DNA Data Bank of Japan (DDBJ) under accession number LC015663. All four parental corals harbored only C3 Symbiodinium (AF499789 (LaJeunesse 2002)). In coral juveniles, sequences of D1 and D1a Symbiodinium were obtained together from each individual; thus, these sequences were considered to be derived from type D1-4, later described as Symbiodinium trenchii (LaJeunesse et al. 2010; LaJeunesse et al. 2014). For further analyses, clade F Symbiodinium was removed as it was found only once throughout the experiments.

\section{Changes in Symbiodinium prevalence among coral juveniles}

The prevalence of Symbiodinium types associated with coral juveniles displayed variable patterns according to the environmental conditions. Generally, the prevalence of type A3 Symbiodinium was high at the beginning of the experiment and then decreased; the prevalence of 
254 type $\mathrm{C} 1$ remained low and increased only at $30^{\circ} \mathrm{C}$; and the prevalence of type $\mathrm{D} 1-4$ increased in 255 both years (Table S1, Fig. 3).

In 2012, the prevalence of type A3 in juveniles was more than $80.0 \%$ at all temperature

257

258

259

260

261

262

263

264

265

266

267

268

269

270

271

272

273

274

275

276

277 conditions initially, but decreased to $15.0 \%-34.2 \%$ after two months. It increased again to $77.5 \%$ after four months at ambient and $30{ }^{\circ} \mathrm{C}$ conditions, but remained around $20 \%$ at $31^{\circ} \mathrm{C}$ (Fig. $3 \mathrm{~A}$ ). The prevalence of type C1 was low (less than 20\%) initially at all temperatures, and then gradually increased up to $36.8 \%$ during the four-month experiment. The range of increase was about $30 \%$ at $30{ }^{\circ} \mathrm{C}$, but less than $15 \%$ under ambient temperatures and at $31{ }^{\circ} \mathrm{C}$. The prevalence of type D1-4 remained high and gradually increased during the four-month experimental period at all temperatures. The prevalence of the three Symbiodinium types A3, C1 and D1 did not significantly differ at the beginning of the experiment among the different temperature conditions (A3: $P=0.621, \mathrm{C} 1: P=0.134, \mathrm{D} 1-4: P=0.610$, Fisher's exact test); however, the prevalence of the three types was significantly different after four months (A3: $P<0.001, \mathrm{C} 1: P$ $<0.001$; D1-4: $P=0.028$, Fisher's exact test). For colonies exposed to temperature conditions of $30{ }^{\circ} \mathrm{C}$, the prevalence of types $\mathrm{A} 3, \mathrm{C} 1$, and D1-4 were $0.0 \%, 25.0 \%$, and $91.7 \%$, respectively, 1.5 years after the experiment began.

In 2013, the prevalence of type A3 was initially high $(63.3 \%-96.4 \%)$ in juvenile corals at all temperatures, and then decreased to $41.4 \%-46.7 \%$ (Fig. 3B). The prevalence of type C1 remained consistently around or lower than $40 \%$ under all temperature conditions. The prevalence of type D1-4 increased in the two heated treatments; the amounts of the increases at $32{ }^{\circ} \mathrm{C}$ varied widely, ranging from $17.2 \%$ to $95.2 \%$ over two months. The prevalence of Symbiodinium types did not significantly differ among temperature conditions at the beginning or after two months (A3: $P=0.960$ [2 months]; C1: $P=0.300$ [0 day]; $P=0.411$ [2 months]; D1-4: $P=0.051$ ), but the prevalence of type A3 at the beginning and type D1-4 after two months 
278 differed significantly $(P=0.006$ and $P<0.001$, respectively, Fisher's exact test).

279

280

281

282

283

284

285

286

287

288

289

290

291

292

293

294

295

296

297

298

299

300

301

\section{Changes in Symbiodinium type compositions in each coral juvenile}

One or multiple Symbiodinium clades/types were found in each individual colony, and these Symbiodinium compositions also changed during the experimental course (Table S2, Figs. 4 and S4).

In $2012,50 \%-60 \%$ of coral juveniles at all temperatures harbored both types A3 and D1-4 simultaneously after two weeks to one month (Fig. 4A). After two months, the number of colonies that harbored only type D1-4 Symbiodinium increased to approximately $60 \%$. After three to four months, under ambient and $30^{\circ} \mathrm{C}$ conditions, colonies harboring only type D1-4 decreased to fewer than $20 \%$, while those harboring multiple clades/types of symbionts increased. In contrast, the number of corals harboring only type D1-4 remained high $(55 \%-65 \%)$ at $31{ }^{\circ} \mathrm{C}$. Additionally, more than $92 \%$ of the colonies at $30{ }^{\circ} \mathrm{C}$ harbored only type D1-4 after 1.5 years (Fig. 4A). Under all temperature conditions, symbiont compositions after four months and 1.5 years were significantly different from those at the beginning of the experiment (Table 1). The compositions in the heated treatments after four months were significantly different from those under ambient conditions.

In $2013,50 \%-70 \%$ of the coral juveniles at all temperatures harbored type $\mathrm{A} 3$ or $\mathrm{C} 1$ Symbiodinium at the beginning of the experiment (Fig. 4B). After two months at $32{ }^{\circ} \mathrm{C}$, colonies harboring only type D1-4 Symbiodinium increased to 52\% conditions (Table S2, Fig. 4B). In heated treatments, the symbiont compositions after two months were significantly different from those at the beginning of the experiment; no significant changes were observed under ambient conditions (Table 1). Among the temperature treatments, symbiont composition was significantly different only between the $32^{\circ} \mathrm{C}$ and ambient conditions. A greater proportion of surviving coral 
302 juveniles harbored only D1-4 Symbiodinium under $31 / 32{ }^{\circ} \mathrm{C}$ conditions compared with the other

303 treatments. This difference was especially visible when considereing the survivorship of coral 304 juveniles (Fig. S4).

305 When we statistically compared the similarities of the symbiont compositions among 306 temperature conditions and time (based on data shown in Table S2), three major clusters formed 307 from the 2012 data (Fig. 5A). One cluster primarily contained data obtained during the early stages of the experiment (cluster I), whereas the other two clusters contained data from the later stages of the experiment. One of these two clusters contained data from the ambient and $30{ }^{\circ} \mathrm{C}$ conditions during both the earlier and later stages (cluster II). The other cluster primarily contained data from the $31^{\circ} \mathrm{C}$ treatment during the later stages (cluster III; Fig. 5A). In 2013, three major clusters also formed (Fig. 5B). The data obtained from the $32^{\circ} \mathrm{C}$ treatment after two months (cluster II) did not cluster with the other data.

\section{DISCUSSION}

This study showed, for the first time, differential survivorships and changes in the associated Symbiodinium community composition in juveniles of the scleractinian coral, A. tenuis, when exposed to high water temperatures over a long period of time (up to four months). Low survivorship of $A$. tenuis juveniles was observed at the highest temperature treatment $\left(31 / 32^{\circ} \mathrm{C}\right)$. It is contrasting that coral juveniles survived up to four months even at $31^{\circ} \mathrm{C}$ in 2012 , but in 2013 those juveniles reared at $32{ }^{\circ} \mathrm{C}$ survived for only two months in 2013 . This may indicate that the lethal temperature threshold for $A$. tenuis juveniles in Okinawa is at $32{ }^{\circ} \mathrm{C}$. In contrast to the highest temperature treatment, high coral survivorship was observed at $30^{\circ} \mathrm{C}$. Coral bleaching occurs when water temperatures higher than the average summer maximum sea surface 
326

327

328

329

330

331

332

333

334

335

temperature persist for an extended period (thermal stress can be estimated using the Degree Heating Week metric) (Glynn 1996; Logan et al. 2012). In this study, the average temperatures in the $30^{\circ} \mathrm{C}$ tanks were $0.50-1.28^{\circ} \mathrm{C}$ above the average ambient temperature during the warmest month (August) in this region. Theoretically, a temperature increase of this magnitude persisting for more than two months could have triggered coral bleaching (Kayanne 2016), however we did not see signs of bleaching. Survivorship in the ambient treatment was lower than at $30{ }^{\circ} \mathrm{C}$. This is perhaps because the temperature was not stable under ambient conditions. Temperatures fluctuated daily, including sudden changes caused by typhoons, and then a decrease decreased in winter. In contrast to survivorship, no significant differences in coral growth were observed between the temperature treatments, suggesting that water temperature does not affect coral growth during the early life stages.

A. tenuis juveniles in this study harbored a greater variety of Symbiodinium types compared with adults; juveniles harbored types A3, C1, D1-4, and F, whereas adults harbored only type C3. This result is consistent with those of previous studies on Acropora spp., showing more flexibility during early ontogeny (Abrego et al. 2009; Abrego et al. 2012; Gómez-Cabrera et al. 2007; Little et al. 2004; Yamashita et al. 2013; Yamashita et al. 2014). Even within the species studied here, A. tenuis, distinct symbiont communities were observed in different locations. In the Great Barrier Reef, juveniles of $A$. tenuis initially acquired Symbiodinium C1, D, or a combination of both (Abrego et al. 2009; Abrego et al. 2012; Little et al. 2004), whereas on Ishigaki Island, southern Japan, these corals hosted clades A, C, D, or a combination of these types, one to six months after settlement (Yamashita et al. 2013). Moreover, in our study, we found for the first time the presence of clade F Symbiodinium in A. tenuis. These differences in acquired Symbiodinium types are believed to be caused by locally-available Symbiodinium communities in sediments and seawater, where free-living algae play roles in the onset of 
350 symbiosis in horizontal transmitters for the acquisition of symbionts (Adams et al. 2009; Cumbo

351 et al. 2012; Nitschke et al. 2015; Yamashita et al. 2013). In this study, Symbiodinium

352 communities in coral juveniles differed between the two years, and this may reflect several

353 factors that differ from year to year. The genetics of juveniles may differ by cohorts and that

354 resulted in differences in symbiont preferences of the juveniles. Water temperatures in ambient

355 tanks were also different among the two years (see Fig. S1), and temperatures higher than 30.5

$356{ }^{\circ} \mathrm{C}$ were observed more frequently in the ambient tanks during 2013. In addition, the number of

357 typhoons that approached Okinawa in 2012 was double the number of those in 2013 (eight and

358 four, respectively; Japan Meteorological Agency). Excessive disturbances may have led to

359 differences in factors such as increased water temperature fluctuations and may also in plankton

360 flora in the water column. Symbiodinium in the water column may also differ. Yamashita et al.

361 (2013) reported that free-living Symbiodinium communities in the water column change over

362 time, and that their compositions were not the same even within the same season .

363 In the present study, the percentage corals harboring only D1-4 Symbiodinium at the highest

364 temperature treatments $\left(31 / 32^{\circ} \mathrm{C}\right)$ increased over time (Fig. 4). Even when the proportions of the

365 symbiont composition were calculated based on coral survivorship, the number of colonies

366 hosting only type D1-4 seemed stable at higher temperatures, particularly in 2012 (Fig. S4).

367 Although the trend in increase was different in 2013, but the prevalence of D1-4 was strikingly

368 increased in higher temperature (Fig. 3B). An increase in only type D1-4-bearing corals was also

369 observed under ambient conditions two months later in 2012, and these symbiont communities

370 were statistically similar to those reared under higher temperatures in later stages of the

371 experiment (Fig. 5). These results may be because the ambient water temperature was sometimes

372 higher than $30^{\circ} \mathrm{C}$ at the time. Clade D Symbiodinium are known to provide heat tolerance to

373 adult corals (Abrego et al. 2008; Baker et al. 2004; Berkelmans \& van Oppen 2006; Fabricius et 
374

375

376

377

378

379

380

381

382

383

384

385

386

387

388

389

390

391

392

393

394

395

396

397

al. 2004; Glynn et al. 2001; LaJeunesse et al. 2008; Rowan 2004; Stat \& Gates 2011; Toller et al. 2001). In juvenile corals, clade D-bearing colonies of $A$. tenuis were thermally less robust when compared with those harboring type $\mathrm{C} 1$ in short-term experiments (Abrego et al. 2008). However, the uptake of clade D Symbiodinium increased under heated conditions $\left(30^{\circ} \mathrm{C}\right.$ and $\left.31^{\circ} \mathrm{C}\right)$ during the onset of symbiosis in A. tenuis and A. millepora (Abrego et al. 2012). Moreover, juveniles of A. tenuis experimentally infected with clade D Symbiodinium exhibited a higher survival rate (Yuyama et al. 2016) and higher carbon acquisition (Baker et al. 2013) than those infected with clade $\mathrm{C} 1$ at $30{ }^{\circ} \mathrm{C}$. Therefore, in our study, the increase in juveniles bearing only type D1-4 at higher temperatures suggests that type D1-4 contributes to the heat tolerance of the juveniles. It is also possible that juveniles hosting a mix of clades, including type D1-4, survived but lost the other clades and/or that they changed their symbiont from other types to D1-4 (symbiont shuffling/switching). In 2012, the prevalence of type D1-4 was stayed high during the experimental period, but those of $\mathrm{A} 3$ and $\mathrm{C} 1$ decreased at highest temperature may exhibit this possibility. Such possibilities have been reported for adults that have experienced bleaching events (Jones et al. 2008; Silverstein et al. 2015), and is termed the "adaptive bleaching hypothesis" (Buddemeier et al. 2004). The differential changes in associated Symbiodinium community composition relating to temperature conditions, as observed in this study, indicate a potential flexibility in changing symbionts. Further studies are required to test this hypothesis by monitoring the same coral individuals over time; however, this approach is challenging due to the small size of the coral juveniles.

The prevalence of A3 Symbiodinium was high at the beginning of the experiments. A3 Symbiodinium is also considered a possible critical symbiotic partner during the early life stages of $A$. tenuis in the Great Barrier Reef, as more robust strains of corals harbor higher proportions of Symbiodinium types A3 and D1 (Quigley et al. 2016). Therefore, this type of symbiont also 
398

399

400

401

402

403

404

405

406

407

408

409

410

411

412

413

plays an important role in A. tenuis survival in Okinawa. A3 Symbiodinium showed a rapid increase under ambient conditions during later periods in the experiment (i.e. winter) in 2012. This finding suggests a cold adaptation of the holobionts. Although decreases in A3 Symbiodinium were observed at higher temperatures during later stages of the experiments, the changes during early stages and under ambient conditions differed between the two years. These differences may be caused by variable environmental conditions, such as fluctuating ambient seawater temperatures between 2012 and 2013 under ambient conditions differed among both years (Fig. S1).

Most of the coral juveniles surviving after 1.5 years at $30^{\circ} \mathrm{C}$ harbored clade D

Symbiodinium. This is in contrast to A. tenuis adults in the northwestern Pacific that are normally associated with clade C Symbiodinium (LaJeunesse et al. 2004; this study), although no comparisons can be made between ambient and heated treatments in the present study. During coral growth, the symbiont communities of the coral juveniles become more specialized (Abrego et al. 2009; Gómez-Cabrera et al. 2007; Little et al. 2004; Yamashita et al. 2013). Abrego et al. (2009) reported that the symbiont communities of $A$. tenuis were homologous to those of adults by 3.5 years of age, and significant changes in the adult-hosted symbiont types were detected by 1.5 years of age in comparison with corals one month after settlement. In contrast, none of the juveniles in this study harbored the C3 Symbiodinium that was harbored by their parents, even 1.5 years later. This may be because our juvenile corals in tanks had no access to the $\mathrm{C} 3$ symbiont including those expelled from adult colonies, but it also may be due to heat treatments altering the coral preference for their symbiont.

Since many corals spawn in late spring to early summer (Harrison 2011; Hayashibara et al. 1993), their new recruits experience the highest seawater temperatures in any given year.

Recently, the frequency of extreme surface seawater temperature events in summer has increased 
422 (Hughes et al. 2017; Kayanne 2016). Moreover, ocean temperatures are gradually increasing and

423 recent simulations indicate that under the worst scenario, sea surface temperatures in the 2090s

424 will be $2.73 \pm 0.72{ }^{\circ} \mathrm{C}$ higher than those experienced in the 1990 s (Bopp et al. 2013). Thus, coral

425 recruits will likely face higher summer seawater temperatures in the future, and hosting multiple

426 symbiont types is probably advantageous to juveniles. Indeed, our results show that coral

427 juveniles may be able to adapt to future climate change by changing their symbiont types,

428 resulting in adult $A$. tenuis hosting more thermally tolerant symbionts. Other adult corals, such as

429 pocilloporids, acroporids, and fungiids, did not change their symbiont types under high thermal

430 conditions in the southern Great Barrier Reef in 2002 (Stat et al. 2009), however, the 2002

431 bleaching event was minor in that region. Therefore, the degree of bleaching is likely dependent

432 upon the combined effects throughout the year, the local environmental conditions, and the

433 species ecological/biological traits. This study focused on symbiont community change, but

434 other factors, such as host coral genetics (Dixon et al. 2015; Palumbi et al. 2014), play roles in

435 the stress tolerance of corals. More studies are needed using different coral genera, different

436 environmental conditions, and physiological/genetic traits to better understand how coral

437 juveniles can acclimatize and/or adapt in the future.

438

439

ACKNOWKLEDGEMENTS

440

We thank Mr. T. Nakajima, Mr. A. Nakamura, Mr. T. Kijima, Ms. S. Okitsu, Ms. A. Muto, Mr.

441

Y. Nakatsuji, and Mr. M. Jinza for their kind help in experimental setup, rearing corals, and

442

molecular analyses. We thank Dr. H. Rouzé and Dr. F. Sinniger for fruitful discussion and

443 comments on the manuscript. Machines for DGGE analyses were kindly provided by Dr. K.

444 Inoue from Atmosphere and Ocean Research Institute, Univ. Tokyo and Dr. N. Shinzato from 445 Center of Molecular Biosciences, Univ. Ryukyus. 


\section{REFERENCES}

Abrego D, Ulstrup KE, Willis BL, and van Oppen MJ. 2008. Species-specific interactions between algal endosymbionts and coral hosts define their bleaching response to heat and light stress. Proc Biol Sci 275:2273-2282. 10.1098/rspb.2008.0180

Abrego D, van Oppen MJ, and Willis BL. 2009. Onset of algal endosymbiont specificity varies among closely related species of Acropora corals during early ontogeny. Mol Ecol 18:3532-3543. 10.1111/j.1365-294X.2009.04276.x

Abrego D, Willis BL, and van Oppen MJ. 2012. Impact of light and temperature on the uptake of algal symbionts by coral juveniles. PLoS One 7:e50311. 10.1371/journal.pone.0050311

Adams LM, Cumbo VR, and Takabayashi M. 2009. Exposure to sediment enhances primary acquisition of Symbiodinium by asymbiotic coral larvae. Marine Ecology Progress Series 377:149-156. 10.3354/meps07834

Baird AH, Guest JR, and Willis BL. 2009. Systematic and biogeographical patterns in the reproductive biology of scleractinian corals. Annual Review of Ecology, Evolution, and Systematics 40:551-571. 10.1146/annurev.ecolsys.110308.120220

Baker AC, Starger CJ, McClanahan TR, and Glynn PW. 2004. Coral's adaptive response to climate change. Nature 430:741.

Baker DM, Andras JP, Jorda'n-Garza AnG, and Fogel ML. 2013. Nitrate competition in a coral symbiosis varies with temperature among Symbiodinium clades. The ISME Journal 7:1248-1251.

Bay LK, Doyle J, Logan M, and Berkelmans R. 2016. Recovery from bleaching is mediated by threshold densities of background thermo-tolerant symbiont types in a reef-building coral. Royal Society Open Science 3:160322.

Berkelmans R, and van Oppen MJ. 2006. The role of zooxanthellae in the thermal tolerance of corals: a 'nugget of hope' for coral reefs in an era of climate change. Proc Biol Sci 273:2305-2312. 10.1098/rspb.2006.3567

Bopp L, Resplandy L, Orr JC, Doney SC, Dunne JP, Gehlen M, Halloran P, Heinze C, Ilyina T, Séférian R, Tjiputra J, and Vichi M. 2013. Multiple stressors of ocean ecosystems in the 21st century: projections with CMIP5 models. Biogeosciences 10:6225-6245. 10.5194/bg-10-6225-2013

Buddemeier RW, Baker AC, Fautin DG, and Jakobs JR. 2004. The adaptive hypothesis of bleaching. In: Rosenverg E, and Loya Y, eds. Coral Health and Disease. Berlin Heidelberg, German: Springer-Verlag, 427-444.

Carpenter KE, Abrar M, Aeby G, Aronson RB, Banks S, Bruckner A, Chiriboga A, Cortes J, Delbeek JC, Devantier L, Edgar GJ, Edwards AJ, Fenner D, Guzman HM, Hoeksema 
484

485

486

487

488

489

490

491

492

493

494

495

496

497

498

499

500

501

502

503

504

505

506

507

508

509

510

511

512

513

514

515

516

517

518

519

BW, Hodgson G, Johan O, Licuanan WY, Livingstone SR, Lovell ER, Moore JA, Obura

DO, Ochavillo D, Polidoro BA, Precht WF, Quibilan MC, Reboton C, Richards ZT, Rogers AD, Sanciangco J, Sheppard A, Sheppard C, Smith J, Stuart S, Turak E, Veron JE, Wallace C, Weil E, and Wood E. 2008. One-third of reef-building corals face elevated extinction risk from climate change and local impacts. Science 321:560-563. 10.1126/science. 1159196

Coffroth MA, and Santos SR. 2005. Genetic diversity of symbiotic dinoflagellates in the genus Symbiodinium. Protist 156:19-34. 10.1016/j.protis.2005.02.004

Cumbo VR, Baird AH, and van Oppen MJH. 2012. The promiscuous larvae: flexibility in the establishment of symbiosis in corals. Coral Reefs 32:111-120. 10.1007/s00338-0120951-7

DeSalvo MK, Sunagawa S, Fisher PL, Voolstra CR, Iglesias-Prieto R, and Medina M. 2010. Coral host transcriptomic states are correlated with Symbiodinium genotypes. Mol Ecol 19:1174-1186. 10.1111/j.1365-294X.2010.04534.x

Dixon GB, Davies SW, Aglyamova GA, Meyer E, Bay LK, and Matz MV. 2015. Genomic determinants of coral heat tolerance across latitudes. Science 348:1460-1462.

Fabricius KE, Mieog JC, Colin PL, Idip D, and van Oppen MJ. 2004. Identity and diversity of coral endosymbionts (zooxanthellae) from three Palauan reefs with contrasting bleaching, temperature and shading histories. Mol Ecol 13:2445-2458. 10.1111/j.1365294X.2004.02230.x

Franklin EC, Stat M, Pochon X, Putnam HM, and Gates RD. 2012. GeoSymbio: a hybrid, cloudbased web application of global geospatial bioinformatics and ecoinformatics for Symbiodinium-host symbioses. Mol Ecol Resour 12:369-373. 10.1111/j.17550998.2011.03081.x

Gómez-Cabrera MdC, Ortiz JC, Loh WKW, Ward S, and Hoegh-Guldberg O. 2007. Acquisition of symbiotic dinoflagellates (Symbiodinium) by juveniles of the coral Acropora longicyathus. Coral Reefs 27:219-226. 10.1007/s00338-007-0315-x

Glynn PW. 1996. Coral reef bleaching: facts, hypotheses and implications. Global Change Biology 2:495-509.

Glynn PW, Maté JL, Baker AC, and Calderón MO. 2001. Coral bleaching and mortality in Panama and Ecuador during the 1997-1998 El Niño-southern oscillation event: spatial/temporal patterns and comparisons with the 1982-1983 event. Bulletin of Marine Science 69:79-109.

Harii S, Hongo C, Ishihara M, Ide Y, and Kayanne H. 2014. Impacts of multiple disturbances on coral communities at Ishigaki Island, Okinawa, Japan, during a 15 year survey. Marine Ecology Progress Series 509:171-180. 10.3354/meps10890 
Harrison PL. 2011. Sexual reproduction of scleractinian corals. In: Dubinsky Z, and Stambler N, eds. Coral Reefs: An Ecosystem in Transition. Dordrecht, Netherlands: Springer Netherlands, 59-85.

Hayashibara T, Shimoike K, Kimura T, Hosaka S, Heyward A, Harrison P, Kudo K, and Omori M. 1993. Patterns of coral spawning at Akajima Island, Okinawa, Japan. Marine Ecology Progress Series 101:253-262.

Hoegh-Guldberg O. 1999. Climate change, coral bleaching and the future of the world's coral reefs. Marine Freshwater Research 50:839-866.

Hoegh-Guldberg O, Mumby PJ, Hooten AJ, Steneck RS, Greenfield P, Gomez E, Harvell CD, Sale PF, Edwards AJ, Caldeira K, Knowlton N, Eakin CM, Iglesias-Prieto R, Muthiga N, Bradbury RH, Dubi A, and Hatziolos ME. 2007. Coral reefs under rapid climate change and ocean acidification. Science 318:1737-1742. 10.1126/science.1152509

Hoegh-Guldberg O, Smith G. J. 1989. The effect of sudden changes in temperature, light and salinity on the populaion density and export of zooxanthellae from the reef coral Stylophora pistillata Exper and Seriatopora hystrix Dana. Journal of Experimental Marine Biology and Ecology 129:279-303.

Hughes TP, Kerry JT, Álvarez-Noriega M, Álvarez-Romero JG, Anderson KD, Baird AH, Babcock RC, Beger M, Bellwood DR, Berkelmans R, Bridge TC, Butler IR, Byrne M, Cantin NE, Comeau S, Connolly SR, Cumming GS, Dalton SJ, Diaz-Pulido G, Eakin CM, Figueira WF, Gilmour JP, Harrison HB, Heron SF, Hoey AS, Hobbs J-PA, Hoogenboom MO, Kennedy EV, Kuo C-y, Lough JM, Lowe RJ, Liu G, McCulloch MT, Malcolm HA, McWilliam MJ, Pandolfi JM, Pears RJ, Pratchett MS, Schoepf V, Simpson T, Skirving WJ, Sommer B, Torda G, Wachenfeld DR, Willis BL, and Wilson SK. 2017. Global warming and recurrent mass bleaching of corals. Nature 543:373-377.

Jones AM, Berkelmans R, van Oppen MJ, Mieog JC, and Sinclair W. 2008. A community change in the algal endosymbionts of a scleractinian coral following a natural bleaching event: field evidence of acclimatization. Proc Biol Sci 275:1359-1365. 10.1098/rspb.2008.0069

Kayanne H. 2016. Validation of degree heating weeks as a coral bleaching index in the northwestern Pacific. Coral Reefs. 10.1007/s00338-016-1524-y

Kayanne H, Harii S, Ide Y, and Akimoto F. 2002. Recovery of coral populations after the 1998 bleaching on Shiraho Reef, in the southern Ryukyus, NW Pacific. Marine Ecology Progress Series 239:93-103.

Kinzie III RA, Takayama M, Santos SR, and Coffroth MA. 2001. The adaptive bleaching hypothesis: experimental tests of critical assumptions. Biological Bulletin 200:51-58.

LaJeunesse TC. 2001. Investigating the biodiversity, ecology, and phylogeny of endosymbiotic 
556

dinoflagellates in the genus Symbiodinium using the ITS region: in search of a "species" level marker. Journal of Phycology 37:866-880.

LaJeunesse TC. 2002. Diversity and community structure of symbiotic dinoflagellates from Caribbean coral reefs. Marine Biology 141:387-400. 10.1007/s00227-002-0829-2

LaJeunesse TC, Bhagooli R, Hidaka M, de Vantier L, Done T, Schmidt GW, Fitt WK, and Hoegh-Guldberg O. 2004. Closely related Symbiodinium spp. differ in relative dominance in coral reef host communities across environmental, latitudinal and biogeographic gradients. Marine Ecology Progress Series 284:147-161.

LaJeunesse TC, Bonilla HR, Warner ME, Schmidt GW, and Fitt WK. 2008. Specificity and stability in high latitude eastern Pacific coral-algal symbioses. Limnology and Oceanography 53:719-727.

LaJeunesse TC, Loh WKW, van Woesik R, Hoegh-Guldberg O, Schmidt GW, and Fitt WK. 2003. Low symbiont diversity in southern Great Barrier Reef corals, relative to those of the Caribbean. Limnology and Oceanography 48:2046-2054.

LaJeunesse TC, Pettay DT, Sampayo EM, Phongsuwan N, Brown B, Obura DO, HoeghGuldberg O, and Fitt WK. 2010. Long-standing environmental conditions, geographic isolation and host-symbiont specificity influence the relative ecological dominance and genetic diversification of coral endosymbionts in the genus Symbiodinium. Journal of Biogeography 37:785-800. 10.1111/j.1365-2699.2010.02273.x

LaJeunesse TC, and Trench RK. 2000. Biogeography of two species of Symbiodinium (Freudenthal) inhabiting the intertidal sea anemone Anthopleura elegantissima (Brandt). Biological Bulletin 199:126-134.

LaJeunesse TC, Wham DC, Pettay DT, Parkinson JE, Keshavmurthy S, and Chen CA. 2014. Ecologically differentiated stress-tolerant endosymbionts in the dinoflagellate genus Symbiodinium(Dinophyceae) Clade D are different species. Phycologia 53:305-319. 10.2216/13-186.1

Little AF, van Oppen MJ, and Willis BL. 2004. Flexibility in algal endosymbioses shapes growth in reef corals. Science 304:1492-1494. 10.1126/science.1095733

Logan CA, Dunne JP, Eakin CM, and Donner SD. 2012. A framework for comparing coral bleaching thresholds. Proceedings of the 12th International Coral Reef Symposium, Cains, Australia, 9-13 July 2012:10A.

Loya Y, Sakai K, Yamazato K, Nakano Y, Sambali H, and van Woesik R. 2001. Coral bleaching: the winners and the losers. Ecology Letters 4:122-131.

Muscatine L, and Porter JW. 1977. Reef corals: mutualistic symbioses adapted to nutrient-poor environments. BioScience 27:454-460.

Nitschke MR, Davy SK, and Ward S. 2015. Horizontal transmission of Symbiodinium cells 
between adult and juvenile corals is aided by benthic sediment. Coral Reefs 35:335-344. $10.1007 / \mathrm{s} 00338-015-1349-0$

Palumbi SR, Barshis DJ, Traylor-Knowles N, and Bay RA. 2014. Mechanisms of reef coral resistance to future climate change. Science 344:895-898. 10.1126/science.1251336

Pochon X, and Gates RD. 2010. A new Symbiodinium clade (Dinophyceae) from soritid foraminifera in Hawai'i. Mol Phylogenet Evol 56:492-497. 10.1016/j.ympev.2010.03.040

Quigley KM, Willis BL, and Bay LK. 2016. Maternal effects and Symbiodinium community composition drive differential patterns in juvenile survival in the coral Acropora tenuis. Royal Society Open Science 3:17.

R Core Team. 2013. R: A language and environment for statistical computing. Available at http://www.R-project.org/.

Rodriguez-Lanetty M, Krupp, D. A., Weis, V. M. 2004. Distinct ITS types of Symbiodinium in Clade C correlate with cnidarian/dinoflagellate specificity during onset of symbiosis. Marine Ecology Progress Series 275:97-102.

Rodriguez-Lanetty M, Wood-Charlson EM, Hollingsworth LL, Krupp DA, and Weis VM. 2006. Temporal and spatial infection dynamics indicate recognition events in the early hours of a dinoflagellate/coral symbiosis. Marine Biology 149:713-719. 10.1007/s00227-0060272-X

Rowan R. 2004. Thermal adaptation in reef coral symbionts. Nature 430:742.

Sampayo EM, Ridgway T, Bongaerts P, and Hoegh-Guldberg O. 2008. Bleaching susceptibility and mortality of corals are determined by fine-scale differences in symbiont type. Proc Natl Acad Sci U S A 105:10444-10449. 10.1073/pnas.0708049105

Santos SR, Taylor DJ, and Coffroth MA. 2001. Genetic comparisons of freshly isolated versus cultured symbiotic dinoflagellates: implications for extrapolating to the intact symbiosis. Journal of Phycology 37:900-912.

Silverstein RN, Cunning R, and Baker AC. 2015. Change in algal symbiont communities after bleaching, not prior heat exposure, increases heat tolerance of reef corals. Glob Chang Biol 21:236-249. 10.1111/gcb.12706

Sinniger F, Reimer JD, and Pawlowski J. 2010. The Parazoanthidae (Hexacorallia: Zoantharia) DNA taxonomy: description of two new genera. Marine Biodiversity 40:57-70. 10.1007/s12526-009-0034-3

Stat M, and Gates RD. 2011. Clade D Symbiodinium in scleractinian corals: a "nugget" of hope, a selfish opportunist, an ominous sign, or all of the above? Journal of Marine Biology 2011:1-9. 10.1155/2011/730715

Stat M, Loh WKW, LaJeunesse TC, Hoegh-Guldberg O, and Carter DA. 2009. Stability of coral-endosymbiont associations during and after a thermal stress event in the southern 
Great Barrier Reef. Coral Reefs 28:709-713. 10.1007/s00338-009-0509-5

Suggett DJ, Warner ME, Smith DJ, Davey P, Hennige S, and Baker NR. 2008. Photosynthesis and production of hydrogen peroxide by Symbiodinium (Pyrrhophyta) phylotypes with different thermal tolerances. $J$ Phycol 44:948-956. 10.1111/j.1529-8817.2008.00537.x

Tchernov D, Gorbunov MY, de Vargas C, Narayan Yadav S, Milligan AJ, Haggblom M, and Falkowski PG. 2004. Membrane lipids of symbiotic algae are diagnostic of sensitivity to thermal bleaching in corals. Proc Natl Acad Sci U S A 101:13531-13535. 10.1073/pnas.0402907101

Toller WW, Rowan R, and Knowlton N. 2001. Repopulation of zooxanthellae in the Caribbean corals Montastraea annularis and M. faveolata following experimental and diseaseassociated bleaching. Biological Bulletin 201:360-373.

van Woesik R, Sakai K, Ganase A, and Loya Y. 2011. Revisiting the winners and the losers a decade after coral bleaching. Marine Ecology Progress Series 434:67-76.

Veron JEN. 2000. Corals of the world. Townsville, Queensland, Australia: Australian Institute of Marine Science.

Weis VM, Davy SK, Hoegh-Guldberg O, Rodriguez-Lanetty M, and Pringle JR. 2008. Cell biology in model systems as the key to understanding corals. Trends Ecol Evol 23:369376. 10.1016/j.tree.2008.03.004

Yamashita H, Suzuki G, Hayashibara T, and Koike K. 2013. Acropora recruits harbor "rare" Symbiodinium in the environmental pool. Coral Reefs 32:355-366. 10.1007/s00338-0120980-2

Yamashita H, Suzuki G, Kai S, Hayashibara T, and Koike K. 2014. Establishment of coral-algal symbiosis requires attraction and selection. PLoS One 9:e97003. 10.1371/journal.pone.0097003

Yorifuji M, Takeshima H, Mabuchi K, Watanabe T, and Nishida M. 2015. Comparison of Symbiodinium dinoflagellate flora in sea slug populations of the Pteraeolidia ianthina complex. Marine Ecology Progress Series 521:91-104. 10.3354/meps11155

Yuyama I, Harii S, and Hidaka M. 2012. Algal symbiont type affects gene expression in juveniles of the coral Acropora tenuis exposed to thermal stress. Mar Environ Res 76:4147. 10.1016/j.marenvres.2011.09.004

Yuyama I, Hayakawa H, Endo H, Iwao K, Takeyama H, Maruyama T, and Watanabe T. 2005. Identification of symbiotically expressed coral mRNAs using a model infection system. Biochem Biophys Res Commun 336:793-798. 10.1016/j.bbrc.2005.08.174

Yuyama I, Nakamura T, Higuchi T, and Hidaka M. 2016. Different Stress Tolerances of Juveniles of the Coral Acropora tenuis Associated with Clades C1 and D Symbiodinium. Zoological Studies 55:19. 10.6620/ZS.2016.55-19 
667 Figure captions

668

669

670

671

672

673

674

675

676

677

678

679

680

681

682

683

684

685

686

687

Fig. 1. Survival rates for juveniles of Acropora tenuis. Numbers of live colonies were counted, and survival curves were obtained using the Kaplan-Meier method.

Fig. 2. Growth of Acropora tenuis juveniles. Mean values of the GMDs (see Materials and Methods) within temperature treatment groups are shown. Bars indicate the maximum and minimum mean values observed among replicates (two in 2012 and three in 2013). ND: no data.

Fig. 3. Prevalence of Symbiodinium types in Acropora tenuis juveniles. The percentage of juveniles that harboring each Symbiodinium type was calculated for each temperature treatment group. Bars indicate the maximum and minimum values of the percentage observed in each replicate (two in 2012 and three in 2013). Numbers of individuals analyzed are shown in Table S1.

Fig. 4. Symbiodinium type compositions within individual colonies of Acropora tenuis juveniles and proportion of juveniles with the same set of symbionts in each temperature treatment group. Numbers of individuals analyzed are shown in Table S2. Arrows indicate the increase in coral juveniles bearing only D1-4 bearing coral juveniles under heated conditions.

687 Fig. 5. Similarities between compositions of detected Symbiodinium types in coral juveniles of 
Acropora tenuis under three temperature treatments during the experimental period. Similarities were evaluated by cluster analyses based on the proportions of juveniles with similar symbiont compositions (data shown in Table S2).

Fig. S1. Water temperatures in the ambient experimental tanks. Water temperatures were hourly measured by a logger set in one of the two (in 2012) or three (in 2013) experimental tanks for each temperature treatment. Weekly mean values of the water temperatures in ambient treatment tanks are shown. Symbols marked on the graph indicate when coral juveniles were collected. The average temperature in the ambient treatment tank of the warmest month (August) was $28.74 \pm$ $0.71{ }^{\circ} \mathrm{C}$ in 2012 and $29.18 \pm 0.55^{\circ} \mathrm{C}$ in 2013.

Fig. S2. Tank experimental design in 2012 (A) and 2013 (B). (C) is showing a tile (10cm x $10 \mathrm{~cm})$ at the beginning of the experiment in 2012 .

Fig. S3. DGGE fingerprints with patterns used to detect Symbiodinium types in this study. Eight patterns of DGGE bands were detected from juvenile corals, while one unique pattern was detected from adult corals. Individual ID indicates [year]-[collection date] [treatment] [replicate] [individual numbers]. See raw data for details of individual coral colonies.

Fig. S4. Symbiodinium type compositions within individual colonies of Acropora tenuis juveniles and their occurrences in surviving individuals. Graphs show data combining Figs. 1 and 4. Numbers of individuals analyzed and observed for each composition are shown in Table S2. 


\section{Table $\mathbf{1}$ (on next page)}

Comparisons of Symbiodinium type compositions in Acropora tenuis juveniles by Fisher's exact test. Number of stars indicate significance of differences. 
1 Table 1 Comparisons of Symbiodinium type compositions in Acropora tenuis juveniles by Fisher's exact 2 test. Number of star indicates significance of differences.

\begin{tabular}{|c|c|c|c|}
\hline Year & Date & Treatment & $P$-value \\
\hline \multirow[t]{8}{*}{2012} & 0 da vs. 4 mo & Ambient & $0.0006^{* *}$ \\
\hline & & $30^{\circ} \mathrm{C}$ & $<0.001 * * *$ \\
\hline & & $31^{\circ} \mathrm{C}$ & $<0.001 * * *$ \\
\hline & 0 da vs. $1.5 \mathrm{yr}$ & $30^{\circ} \mathrm{C}$ & $<0.001 * * *$ \\
\hline & $0 \mathrm{da}$ & Ambient vs. $30^{\circ} \mathrm{C}$ & 0.244 \\
\hline & & Ambient vs. $31^{\circ} \mathrm{C}$ & 0.435 \\
\hline & $4 \mathrm{mo}$ & Ambient vs. $30^{\circ} \mathrm{C}$ & $0.003^{*}$ \\
\hline & & Ambient vs. $31^{\circ} \mathrm{C}$ & $<0.001 * * *$ \\
\hline \multirow[t]{7}{*}{2013} & 0 da vs. 2 mo & Ambient & 0.238 \\
\hline & & $30^{\circ} \mathrm{C}$ & $<0.001 * * *$ \\
\hline & & $32^{\circ} \mathrm{C}$ & $<0.001 * * *$ \\
\hline & $0 \mathrm{da}$ & Ambient vs. $30^{\circ} \mathrm{C}$ & 0.019 \\
\hline & & Ambient vs. $32^{\circ} \mathrm{C}$ & 0.060 \\
\hline & $2 \mathrm{mo}$ & Ambient vs. $30^{\circ} \mathrm{C}$ & 0.410 \\
\hline & & Ambient vs. $32^{\circ} \mathrm{C}$ & $0.003 *$ \\
\hline
\end{tabular}

3 


\section{Figure 1 (on next page)}

\section{Graphs of survivorship}

Fig. 1. Survival rates for juveniles of Acropora tenuis . Numbers of live colonies were counted, and survival curves were obtained using the Kaplan-Meier method. 

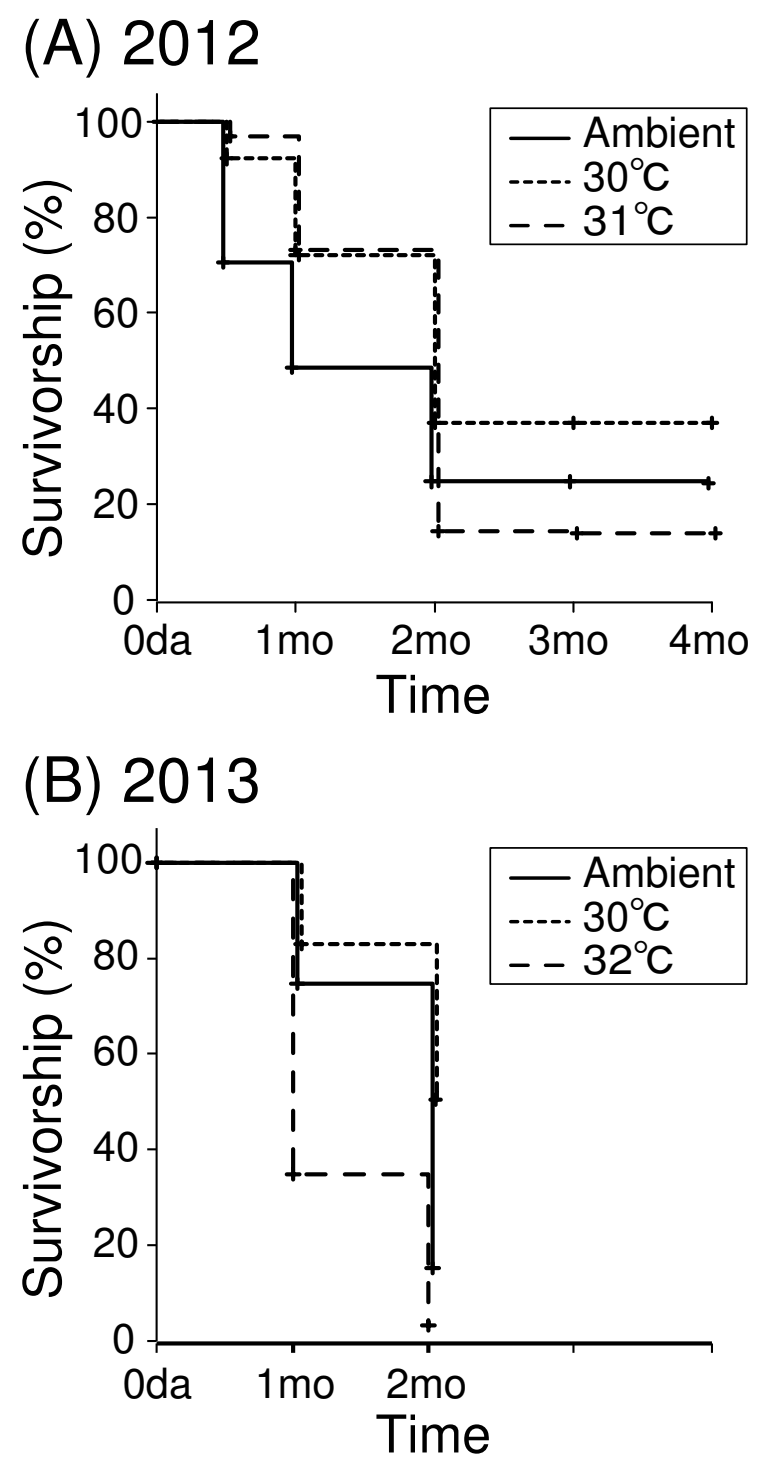


\section{Figure 2 (on next page)}

\section{Graphs of coral growth}

Fig. 2. Growth of Acropora tenuis juveniles. Mean values of the GMDs (see Materials and Methods) within temperature treatment groups are shown. Bars indicate the maximum and minimum mean values observed among replicates (two in 2012 and three in 2013). ND: no data. 
(A) 2012

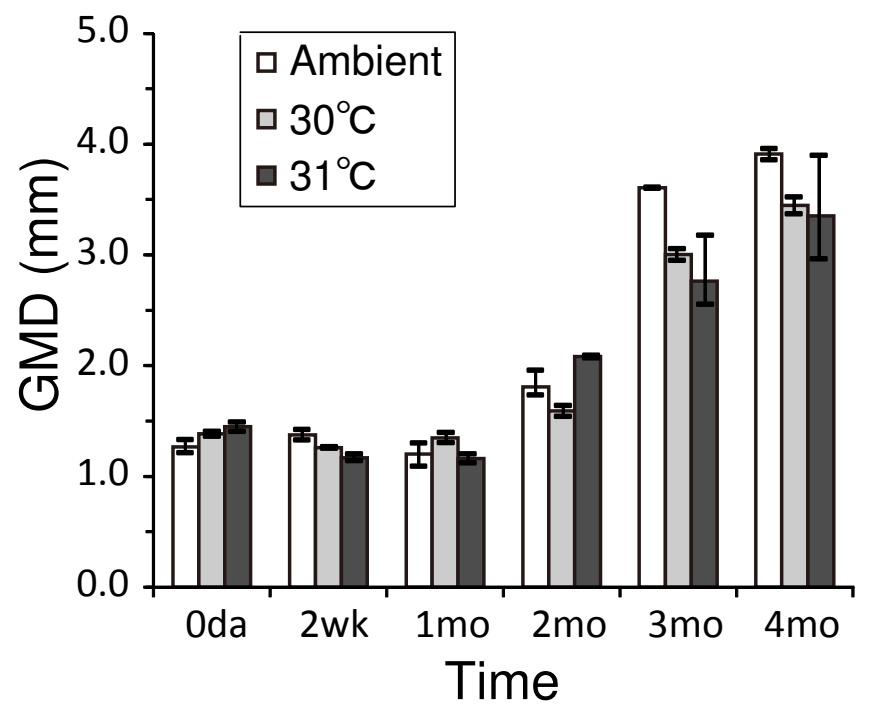

(B) 2013

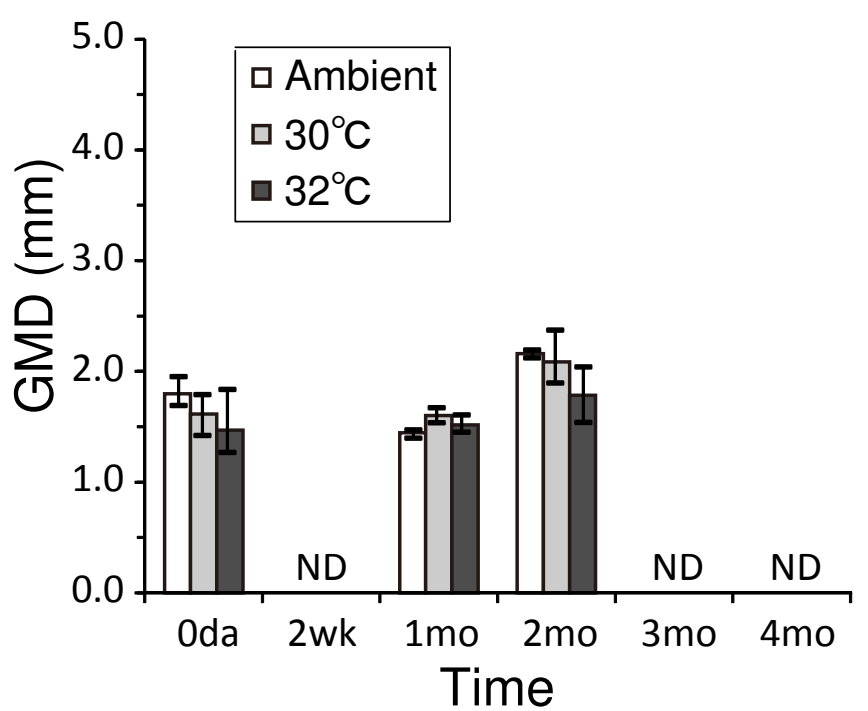


Figure 3 (on next page)

Graphs of symbiont prevalence

Fig. 3. Prevalence of Symbiodinium types in Acropora tenuis juveniles. The percentage of juveniles that harboring each Symbiodinium type was calculated for each temperature treatment group. Bars indicate the maximum and minimum values of the percentage observed in each replicate (two in 2012 and three in 2013). Numbers of individuals analyzed are shown in Table S1. 
(A) 2012
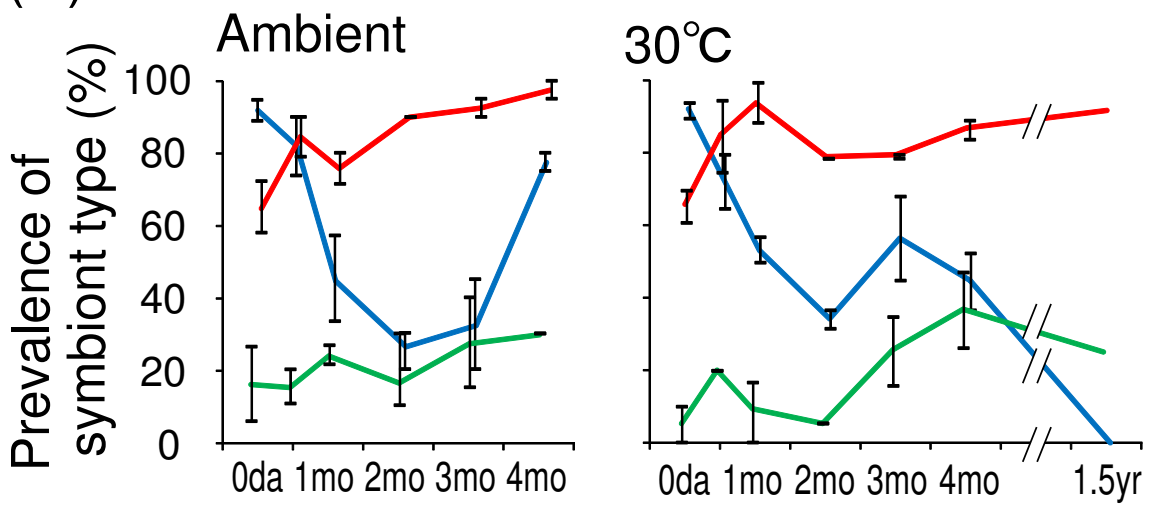

$31^{\circ} \mathrm{C}$

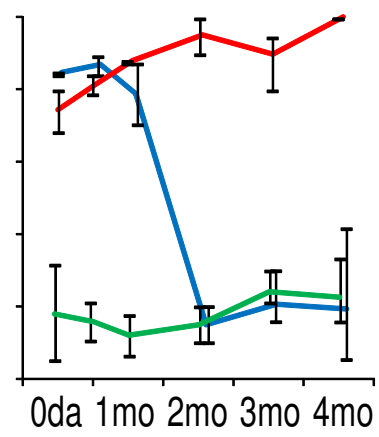

Time

(B) 2013

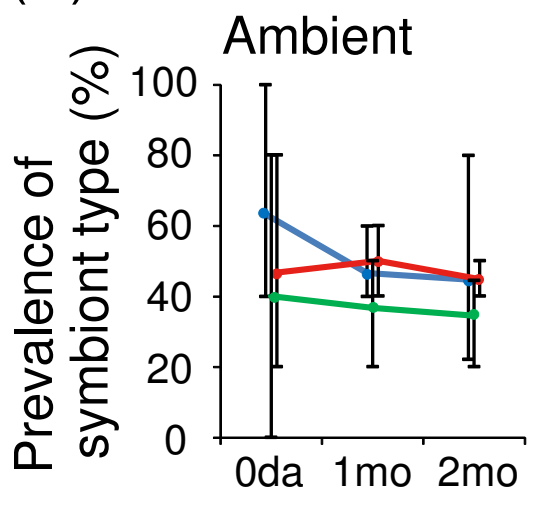

$30^{\circ} \mathrm{C}$

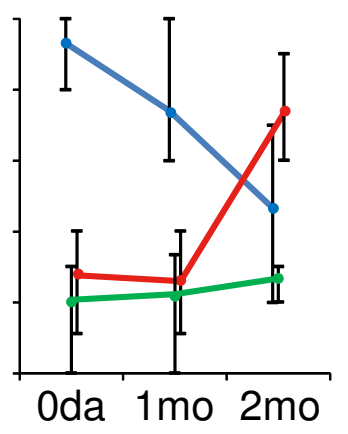

Time $32^{\circ} \mathrm{C}$

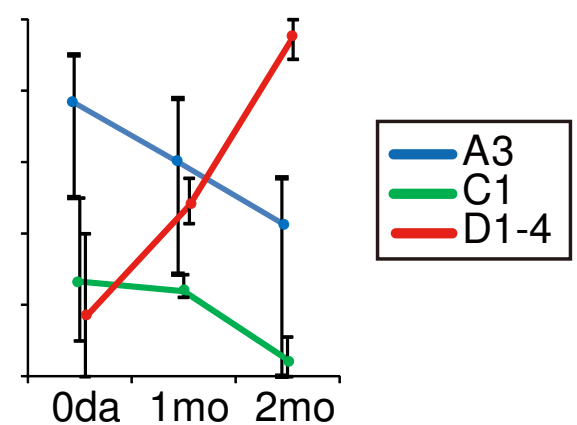




\section{Figure 4 (on next page)}

\section{Graphs of symbiont compositions and their occurrences}

Fig. 4. Symbiodinium type compositions within individual colonies of Acropora tenuis juveniles and proportion of juveniles with the same set of symbionts in each temperature treatment group. Numbers of individuals analyzed are shown in Table S2. Arrows indicate the increase in coral juveniles bearing only D1-4 bearing coral juveniles under heated conditions. 
(A) 2012

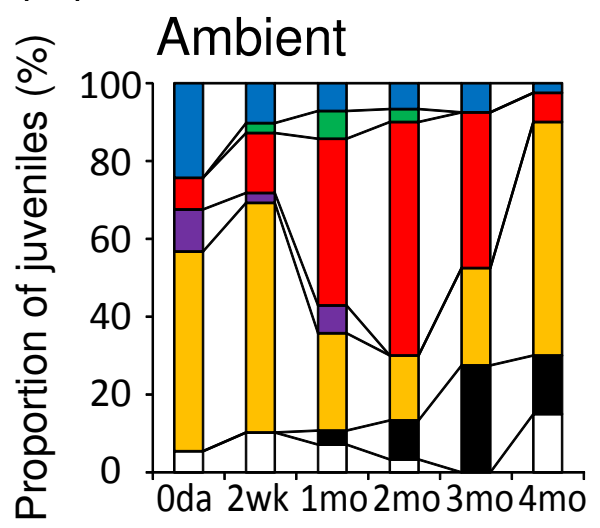

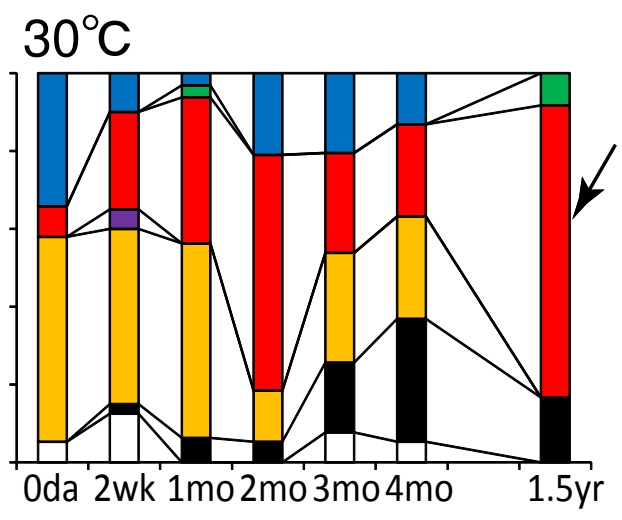
Time $31^{\circ} \mathrm{C}$

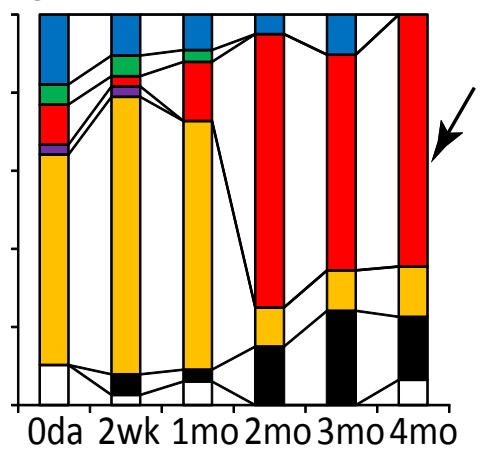

Oda 2 wk $1 \mathrm{mo} 2 \mathrm{mo} 3 \mathrm{mo} 4 \mathrm{mo}$

(B) 2013

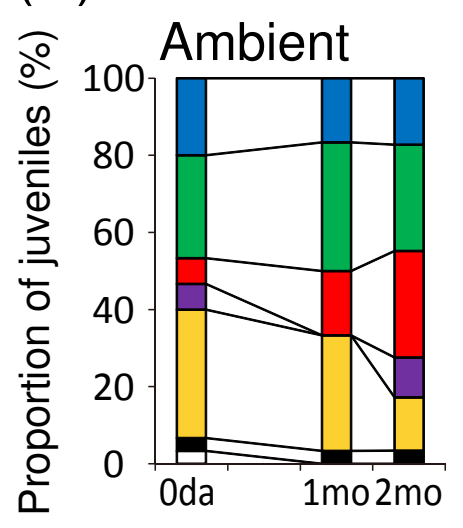

$30^{\circ} \mathrm{C}$

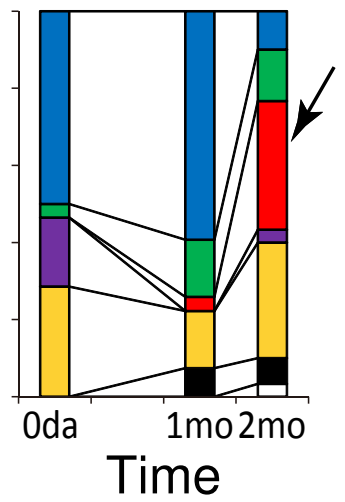

$32^{\circ} \mathrm{C}$

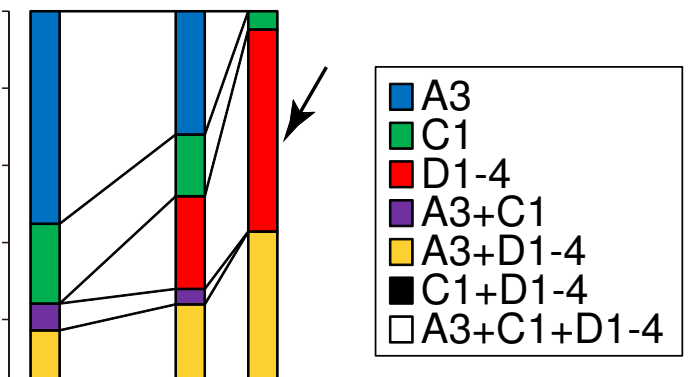

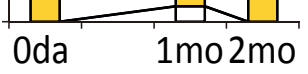

Oda $1 \mathrm{mo} 2 \mathrm{mo}$ 
Figure $\mathbf{5}$ (on next page)

Dendrograms showing similarlity/difference of symbiont communities

Fig. 5. Similarities between compositions of detected Symbiodinium types in coral juveniles of Acropora tenuis under three temperature treatments during the experimental period. Similarities were evaluated by cluster analyses based on the proportions of juveniles with similar symbiont compositions (data shown in Table S2). 
(A) 2012

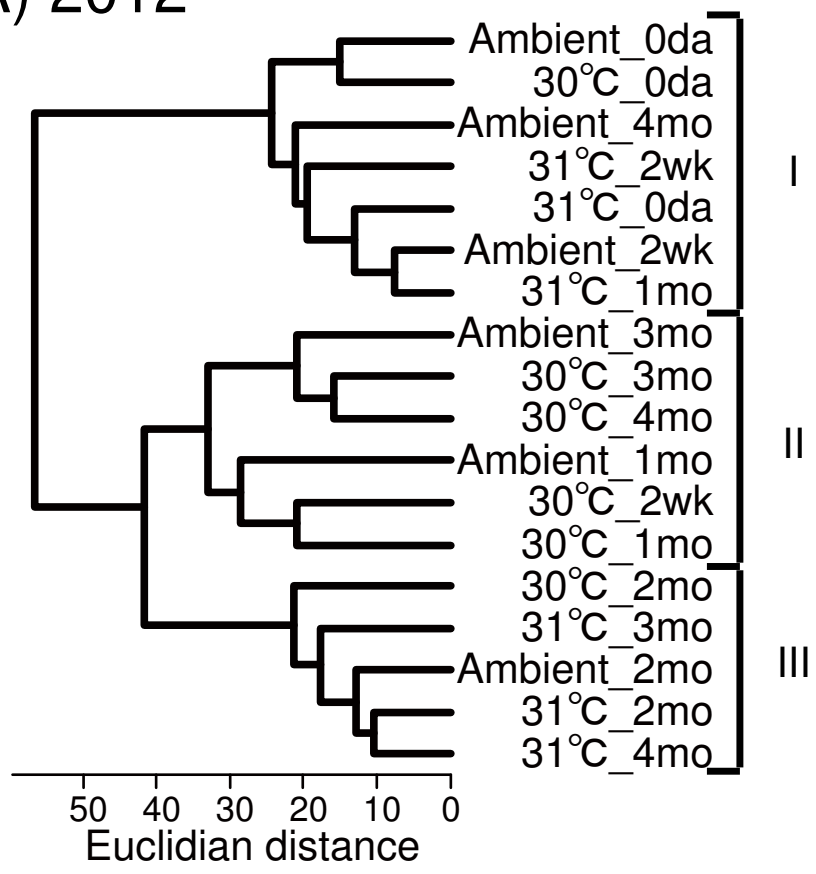

(B) 2013

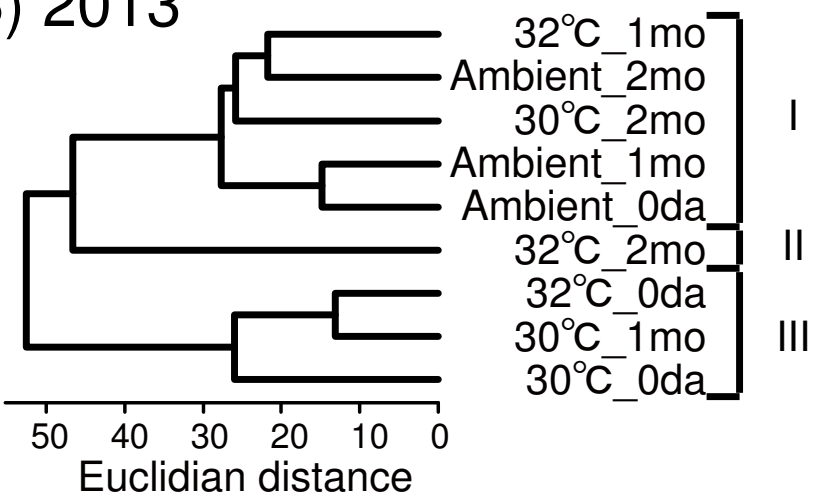

